\title{
EFFECT OF NIOBIUM ADDITION ON STAMPING TOOL STEEL PROPERTIES
}

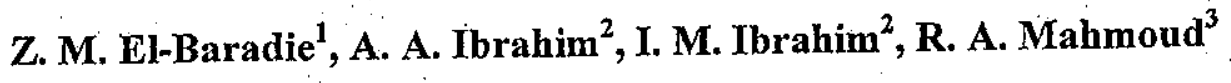 \\ ${ }^{1}$ Central Metalurgical Research and Development Institute (CMDRI), National \\ Research Center, Cairo, Egypt \\ ${ }^{2}$ Mechanical Engineering Department, Shoubra Faculty of Engineering, Benha \\ University, Cairo, Egypt \\ ${ }^{3}$ Aircraft Engine Factory, Arabic Association for Industrialization, Helwan, \\ Egypt
}

\begin{abstract}
High carbon - high chromium cold work tool steel type D3 containing $2 \% \mathrm{C}$ and $12 \% \mathrm{Cr}$ was commonly used for manufacturing stamping tools. This paper introduces an investigation for the effect of inoculation of this type of tool steel by niobium. Four grades of this tool steel containing $0,0.03 \%, 0.04 \%$ and $0.05 \% \mathrm{Nb}$ were casted in an induction furnace at $1600^{\circ} \mathrm{C}$. Different treatment processes including annealing, forging, stress relief, hardening, and tempering were carried out for the casted alloy. Examination via optical microscopy, $\mathrm{X}$ - ray diffraction, hardness test, tensile test, and dimensional wear coefficient and wear rate measurements has been investigated. Furthermore the fracture surfaces were examined using SEM microscope.

The tool steel containing both $\mathrm{Nb}$ carbides and $\mathrm{Cr}$ carbides exhibited a higher hardness, toughness, and wear resistance in comparison with tool steel containing only $\mathrm{Cr}$ carbides. On the other hand, the addition of $\mathrm{Nb}$ increased hardenability, and led to the refinement of the tool steel grain structure. The microstructure observation revealed that, the tool steel coritaining both $\mathrm{Nb}$, and $\mathrm{Cr}$ exhibited fine and uniformly distributed metal carbides, while, the carbides were coarse and sparsely distributed in the tool steel containing $\mathrm{Cr}$ only. As niobium content increases, the improvement of the mechanical properties and wear resistance were observed.

Fracture surface examination indicating that, $\mathrm{Nb}$ addition and hardening followed by tempering process lead to changing the mode of fracture from cleavage to quasi - cleavage mode. The highest wear resistance can be achieved by hardening followed by tempering of $0.05 \% \mathrm{Nb}$ tool steel.
\end{abstract}

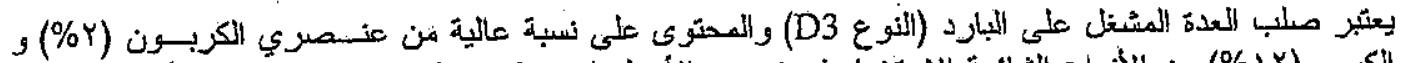

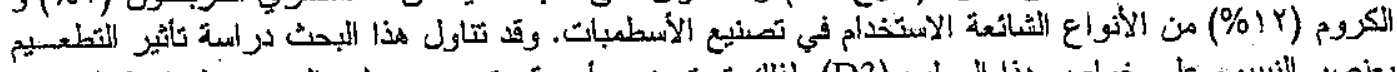

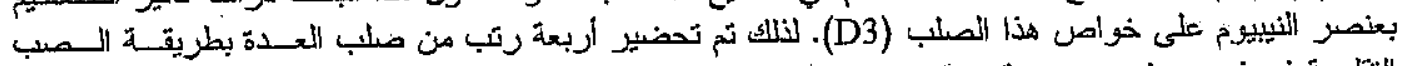

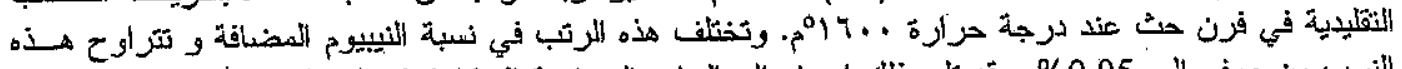

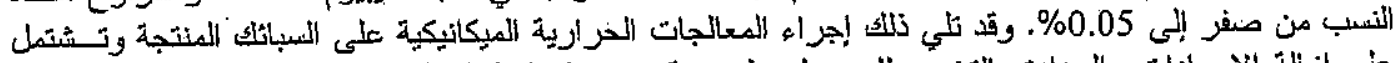

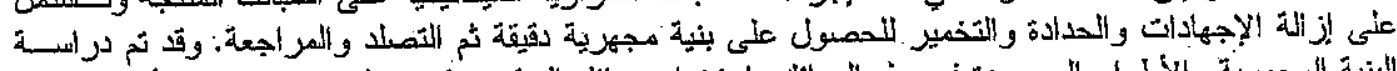

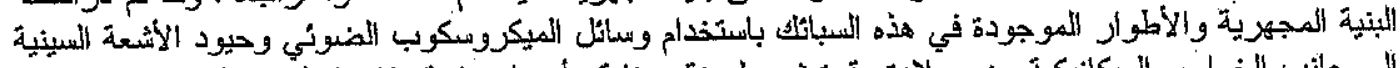

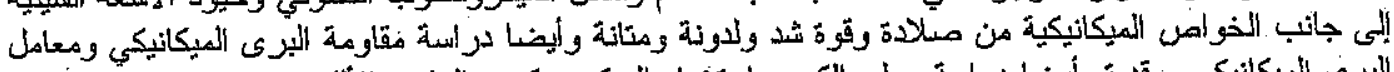

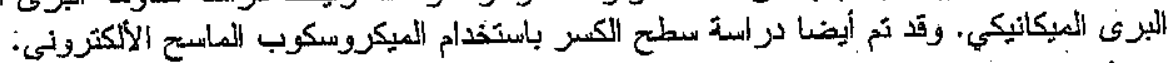

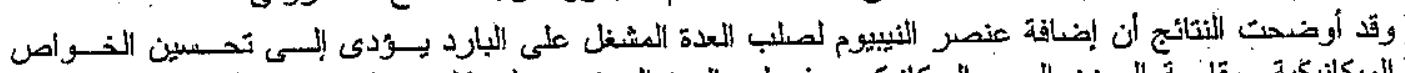

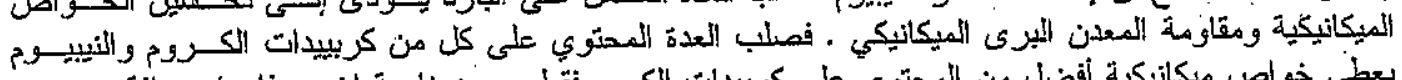

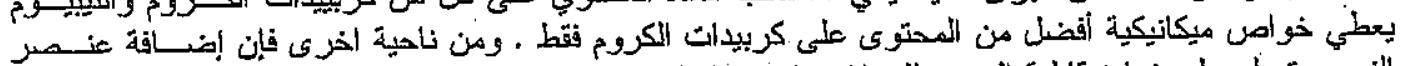

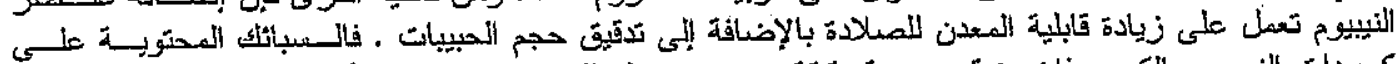

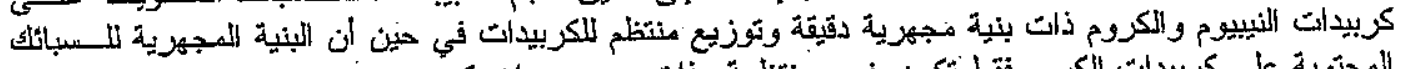

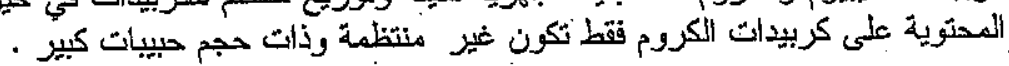

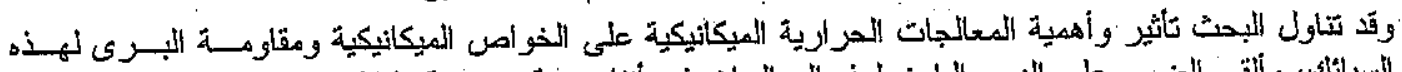

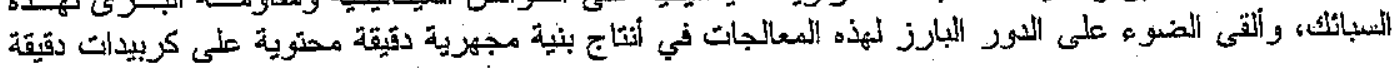




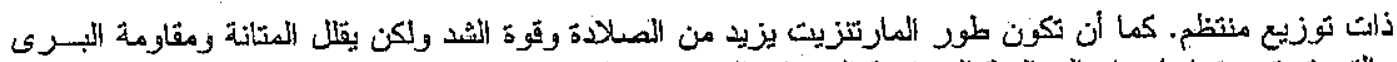

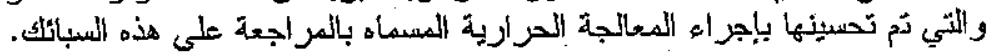

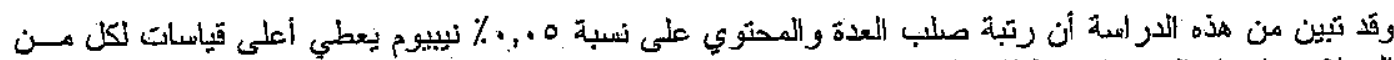

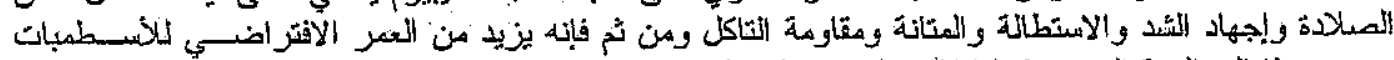

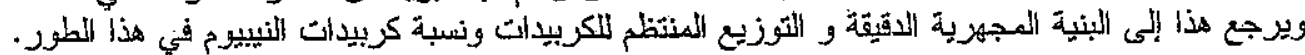

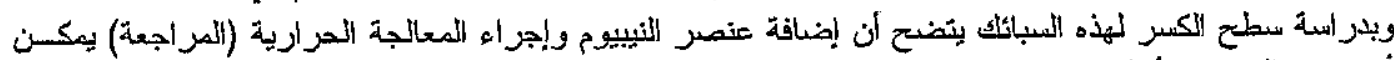

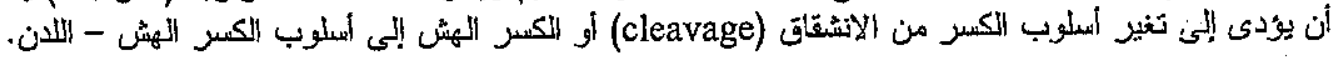

Keywords: Niobium, inoculation, tool steel, mechanical properties

\section{INTRODUCTION}

Tool steel is an alloy steel used to make tools for cutting, forming or otherwise shaping a material into a part or component adapted to a definite use. In cold forming, tools are exposed to extremely high loads due to the high required forming stresses and the strain hardening of the workpiece material. Hence, the improvement of tool technology plays a key role for increasing the tool life which will improve the innovation and competitiveness of the companies as well as open up new product ranges [1].

Great efforts were done by many authors to improve the tool performance. K. Wagner et al. [2] in 2008 attempted to increase tool life through surface enhancement. In their paper, three different methods were investigated: hard roller burnishing, surface heat treatment by laser and laser surface texturing. Finite element analysis has been employed to identify the optimum surface treatment. Surface textures improves the tribological state and it was proved already in some industrial applications to increase tool life distinctly e.g. for punches. Friction and wear are - among other parameters - significantly dependent on the surface topography of the tool and the workpiece [3].

Tool steels contain, among other elements, relatively large amount of tungsten, molybdenum, manganese, vanadium and chromium. These elements have made it possible to meet increasingly severe service demands and to provide greater dimensional control and resistance to cracking during heat treatment. A study for the influence of vanadium on the ion nitriding process and the abrasive wear of tool steels produced by powder metallurgy materials was presented by Riofano et al.[4]. Their results have revealed that, the hardness of the layers increased considerably after nitriding process.

Many specific grades of tool steels are used for several manufacturing applications. One of which is cold work tool steel (D - grades) with $12 \% \mathrm{Cr}$ and 1.5 to $2.3 \% \mathrm{C}$. These types are widely used for manufacturing tools in metal cutting and forming. The mechanical properties and the wear resistance of these hypoeutectic steels depend on their microstructure. As the carbon content is raised the volume content of chromium carbides increases [5].
Niobium (Columbium) carbide-forming element is a newcomer to this field which is progressively finding its way into a variety of tool steels. The basic consideration when applying niobium to steels is that it forms very stable carbides to facilitate grain refinement and precipitation hardening as strengthening mechanisms in structural steels.

The present work introduces an investigation for the effect of niobium addition in the range of 0.03 to $0.05 \%$ on the properties of stamping tool steel. The microstructure examination will be taken in consideration. It is aimed to achieve that conditions which improve the mechanical properties, wear resistance, and heice increase the tool life of stamping. This experimental work includes casting, forging, and several beat treatments to achieve this aim.

\section{EXPERIMENTAL PROGRAM}

The enhancement of stamping tool steel properties (life) by different additions of $\mathrm{Nb}$ and subsequent treatment is the ultimate aim of the present work. Therefore, both of microstructure and fracture surface were examined in addition to the grain refinement and carbides formation. Also, Rockwell hardness test (HRC), tensile test and sliding wear test were conducted. The X-ray diffraction and scanning electron microscope SEM, were employed for phase and fracture surface analysis, respectively.

The material used in this study is high carbon - high chromium D3 tool steel. The standard D3 tool steel of DIN 1.2080 has the chemical composition listed in Table 1. Four grades from this material were prepared for the investigation.

A wooden pattern type $Y$ shape shown in Fig. 1 was used for forming the mould to produce the required tool steel according to standard PN 004206.

Green molding sand technique was used as a molding material for the casting process. This molding sand is a mixture of silica sand of zafrana of 60 AFS, clay (binder) and water. Binder is sodium bantonite, cereal binders, starch or dextrin are often added to improve molding properties.

The used steel was melted using a medium frequency induction furnace of 0.5 ton capacity. The furnace 
was charged with the received steel, and then the charge was melted down under stirring action, which helps to accelerate melting process and improve the homogenity of molten metal. After 30-35min. melting was completed, at $\left(1600^{\circ} \mathrm{C}\right)$, then chemical analysis was carried out by spectrometer.

It was found that, the carbon content was low, so iron carbide was added to the furnace to increase carbon content to the required level. The final chemical composition of the molten steel is introduced in Table 2.

Then the molten metal was deoxidized by adding $1 \%$ Al per ton of molten steel, and then poured in two mould cavities (Fig.1) to form the required castings. This is considered as the standard alloy D3 grade (A), without the $\mathrm{Nb}$ addition.

Table 1. Standard chemical composition of D3 DIN 1.2080

\begin{tabular}{|c|c|c|c|c|c|c|c|c|c|c|c|c|}
\hline $\mathrm{C}$ & $\mathrm{Si}$ & $\mathrm{Mn}$ & $\mathrm{P}$ & $\mathrm{S}$ & $\mathrm{Cr}$ & $\mathrm{Mo}$ & $\mathrm{Ni}$ & $\mathrm{Al}$ & $\mathrm{Cu}$ & $\mathrm{Ti}$ & $\mathrm{V}$ & $\mathrm{Nb}$ \\
\hline $2-2.2$ & $0.1-0.4$ & $0.15-0.45$ & $\leq 0.03$ & $\leq 0.03$ & $11-12$ & - & - & $\ldots$ & - & - & - & - \\
\hline
\end{tabular}

Table 2. Chemical composition of first grade steel (grade A)

\begin{tabular}{|c|c|c|c|c|c|c|c|c|c|c|c|c|}
\hline $\mathrm{C}$ & $\mathrm{Si}$ & $\mathrm{Mn}$ & $\mathrm{P}$ & $\mathrm{S}$ & $\mathrm{Cr}$ & $\mathrm{Mo}$ & $\mathrm{Ni}$ & $\mathrm{Al}$ & $\mathrm{Cu}$ & $\mathrm{Ti}$ & $\mathrm{V}$ & $\mathrm{Nb}$ \\
\hline 2 & .29 & .44 & .017 & .004 & 12 & .007 & .08 & .027 & .032 & .003 & .07 & .007 \\
\hline
\end{tabular}

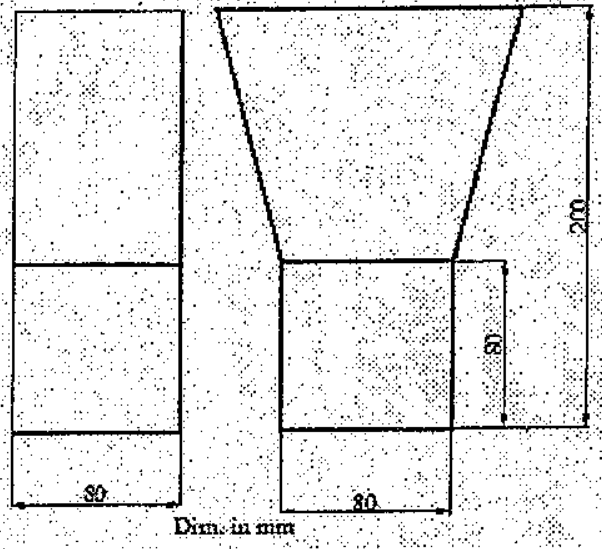

Fig. 1 Geometry of the wooden pattern

\subsection{Niobium addition}

Since, it is required to investigate the $\mathrm{Nb}$ addition on stamping tool steel properties; the niobium was added to the first grade steel as a Feroniobium with the chemical composition shown in table 3 .

Table 3. Chemical composition of the Ferroniobium

\begin{tabular}{|c|c|c|c|c|}
\hline $\mathrm{Nb}$ & $\mathrm{C}$ & $\mathrm{P}$ & $\mathrm{Si}$ & $\mathrm{S}$ \\
\hline $67 \%$ & $0.4 \%$ & $0.1 \%$ & $10 \%$ & $0.1 \%$ \\
$\mathrm{~min}$ & $\max$ & $\max$ & $\max$ & $\max$ \\
\hline
\end{tabular}

Different tool steel grades were prepared with $2.2 \% \mathrm{C}, 11.7 \% \mathrm{Cr}$, and three $\mathrm{Nb}$ contents to obtain different grades. These grades are as follows: grade $\mathrm{B}$ $0.03 \% \mathrm{Nb}$, grade C $0.04 \% \mathrm{Nb}$, and grade D $0.05 \% \mathrm{Nb}$.

\subsection{Thermal treatment.}

Annealing: This was done for all steel grades in order to improve formability and relief the residual stresses due to the casting process. The castings were heated in a muffle furnace (Ney craft model) up to $800^{\circ} \mathrm{C}$, holding for 3 hours, cooling slowly in the furnace down to $600^{\circ} \mathrm{C}$ at a rate of $20^{\circ} \mathrm{C}$ per hour.
Then the castings were cooled in air to room temperature.

Forging: After annealing process, the specimens were preheated to $700{ }^{\circ} \mathrm{C}$ before raising its temperature to the final forging temperature $1050^{\circ} \mathrm{C}$. This was done in order to avoid cracking due to rapid heating, then the specimen were adjusted on the lower die forge of the press. The forging press was performed to reduce cross- section diameter from 80 $\mathrm{mm}$ to $25 \mathrm{~mm}$.

Stress relief annealing: The forged bars were subjected to a final annealing process at a temperature $650^{\circ} \mathrm{C}$, for 2 hours, then cooled in forced air to improve the machinability of the forged bars.

Hardening and Tempering: The specimens after machining were hardened by heating to $960^{\circ} \mathrm{C}$, then quenched in hot oil $\left(180-200^{\circ} \mathrm{C}\right)$ for 5 miriutes, and then cooled in forced air. The subsequent tempering process was done at $270^{\circ} \mathrm{C}$ for one hour, and then cooled in air.

\section{2-3 Material characterization}

The material under investigation was subjected to some metallurgical tests to examine its properties. The tests are as follows:-

\section{2-3-1 Microstructure examination}

For optical microscopy, specimens of the different grades of steels were prepared according to the following schedule; specimens were ground on successive grinding papers (to 1200 grit) and finally polished with $1 / 4 \mu \mathrm{m}$ diamond paste. After that, the polished specimens were etched in Nital solution (3\%HNO3, 97\% alcohol).Fractured surfaces of typical specimens subjected to tensile tests were examined using a scanning electron microscope (SEM) Jeol 5410. 


\section{2-3-2 X-Ray diffraction}

$X$ - ray diffraction analysis was carried out using BRUKER advanced $x$-ray solution (BRUKER axes $\mathrm{D} 8$ advance). The pattern was run with a $\mathrm{Cu}$ target with secondary mono- chrometer. This device is computerized in such way that all the information needed are produced on the computer print sheet.

\section{2-3-3 Mechanical Testing}

The tool steel used in punches must be having specific mechanical properties. The mechanical properties carried on the material under investigation were as follows;

\section{2-3-3-1 Hardness Measurements}

Specimens of all grades of steel in as cast and as heat treated conditions were prepared for hardness tests by using Rockwell hardness tester. A minimum of six measurements were made for each case.

\section{2-3-3-2 Tensile Test}

Tensile tests were conduced to failure on as forged as well as heat treated specimens (50 mm gauge length, $10 \mathrm{~mm}$ gauge diameter and threaded end) according to DIN50125 using Instron universal testing machine at room temperature. The cross head speed was 10 $\mathrm{mm} / \mathrm{min}$ and average of three observations had been considered in this work.

\section{2-3-3-3 Impact Test}

For each type of steel, standard notched charpy specimens were test according to the standard test [ASTWE]. An average of three observations had been considered in this work.

\section{2-3-4 Sliding wear test}

The forming operation which employ punches and dies are frequently exposed to conditions of repetitive impact sliding, therefore, the different steel grades were subjected to the sliding wear test. Dry sliding wear tests were carried using pin on disc type machine on cylindrical specimens $(20 \mathrm{~mm}$ long and 8 mm diameter) against a shell wheel of $200 \mathrm{~mm}$ diameter and of surface hardness $75 \mathrm{HRC}$. The amount of weight loss due to wear of the pins was measured on an electric balance with accuracy of $\pm 0.01 \mathrm{mg}$. The sliding parameters selected in the

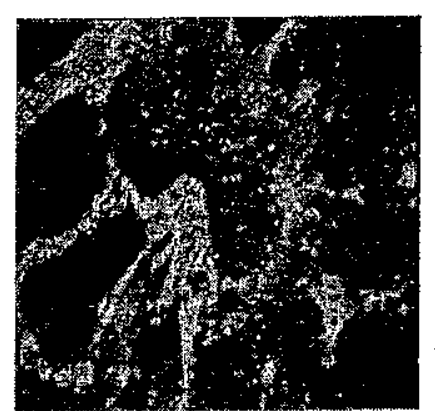

(a) Grade A $(0 \% \mathrm{Nb})$

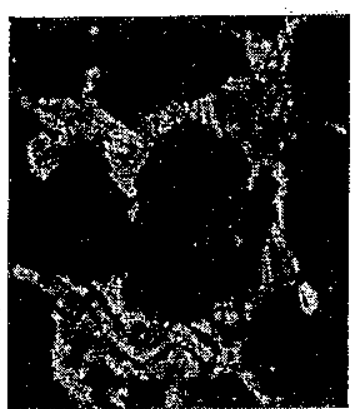

(b) Grade B $(0.03 \% \mathrm{Nb})$

present study are; speed of rotation of the disc 200 $\mathrm{rpm}$, corresponding to linear velocity at the friction interface of $2.1 \mathrm{~m} / \mathrm{sec}$, sliding distance $630 \mathrm{~m}$, and applied pressure $10 \mathrm{~N}$.

The weight loss is used as an indication of wear resistance and it is used to determine the dimensional wear coefficient according to the following equation [6],

Where:

$$
\mathrm{K}=\mathrm{Q} / \mathrm{P} \quad\left(\mathrm{mm}^{3} / \mathrm{N} . \mathrm{m}\right)
$$

$\mathrm{P}=\operatorname{applied} \operatorname{load}(\mathrm{N})$

$\mathrm{Q}=$ volume worn per unit sliding distance $(\mathrm{V} / \mathrm{L})$

$\mathrm{V}=$ weight loss $(\mathrm{g}) /$ density $\left(\mathrm{g} / \mathrm{mm}^{3}\right)$

\section{RESULTS AND DISCUSSIONS}

\subsection{Microstructure Examination}

The microstructures were examined for as cast and heat treated tool steel grades. In general, the microstructure examination indicates no defects for as cast as well as heat treated specimens.

\subsubsection{As cast microstructures}

The effect of $\mathrm{Nb}$ addition on the microstructure of as cast tool steel is given in Fig. 2 (a-d). It is observed that, by increasing the $\mathrm{Nb}$ content, the grain refinement is increased and the gray carbides become clear in the matrix, especially in steel grade D. By the help of X-ray diffraction, the $(\mathrm{Fe}+\mathrm{NbC})$ eutectic phase is detected as shown in Fig.3.

To eliminate the introduced residual stresses and improve the forgeability, all steel grades were subjected to the annealing process. It is observed that, there in no appreciable effect of that treatment on the microstructure, as shown in Fig. 4.

\subsubsection{Stress relief for forged specimens}

The stress relief annealing treatment provides uniform microstructure for the subsequent hardening treatment; also it enhances the machinability of the forged tool steel specimens. The microstructure of stress relieved specimen reveals a uniform distribution of coarse and fine spheroidized chromium carbide particles $\left(\mathrm{Cr}_{7} \mathrm{C}_{3}\right)$. It is clear that, the niobium addition refined the grains structure as shown in Fig. $5(\mathrm{a}-\mathrm{b})$.

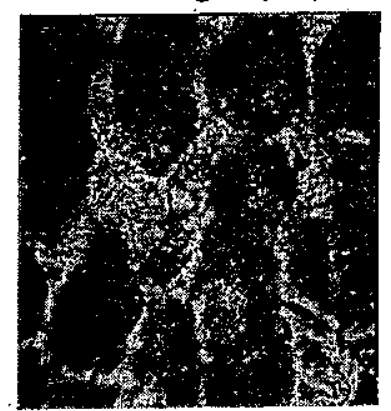

(c) Grade C $(0.04 \% \mathrm{Nb})$

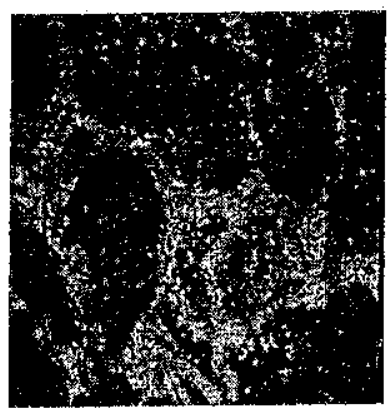

(d) Grade $\mathrm{D}(0.05 \% \mathrm{Nb})$

Fig.2 Microstructure of as cast specimen for different tool steel grades $(500 \mathrm{X})$ 


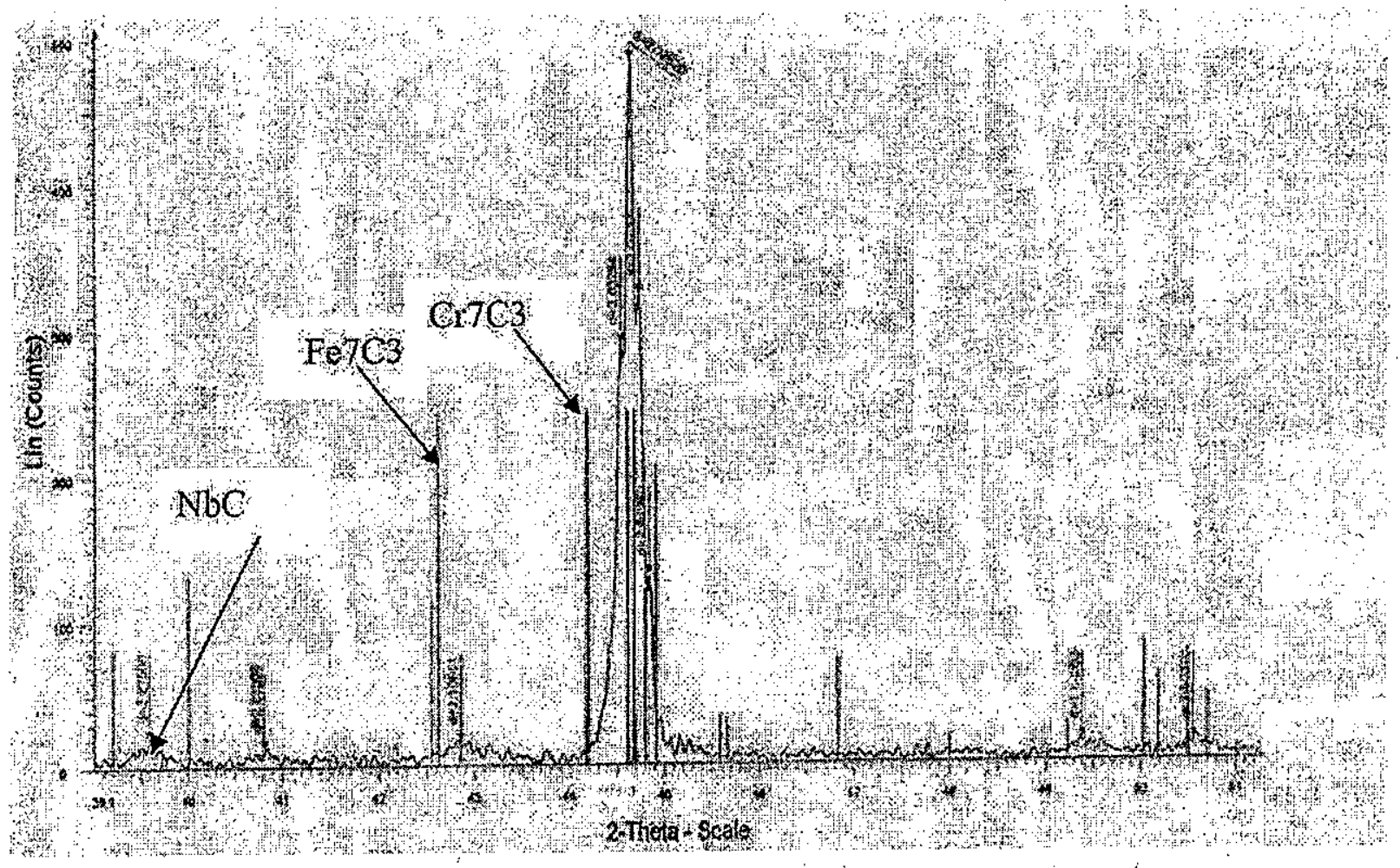

Fig.3 X- Ray diffraction analysis of as cast grade D steel (\% $0.05 \mathrm{Nb})$

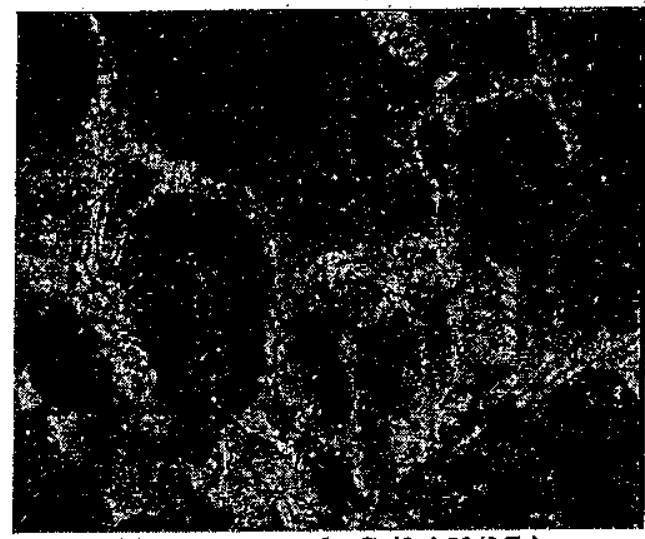

(a) As cast grade $\mathrm{C}(0.05 \% \mathrm{Nb})$

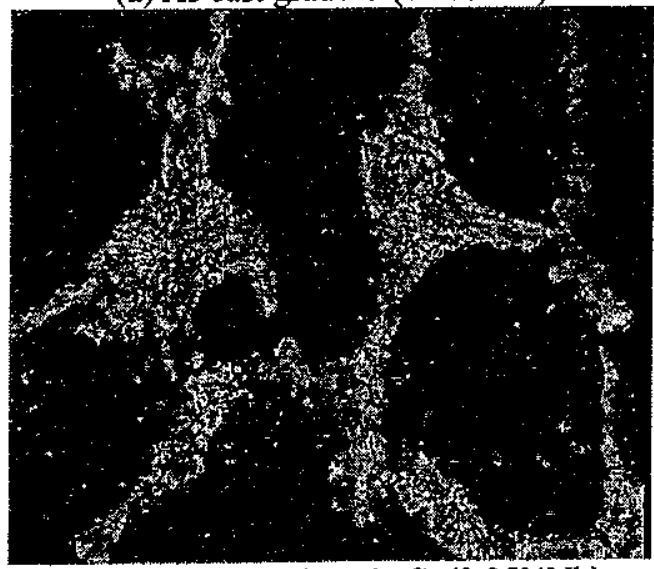

(b) After annealed grade $\mathrm{C}(0.05 \% \mathrm{Nb})$

Fig. 4 Microstructure of as cast and annealed grade $\mathrm{C}$ steel $(500 \mathrm{X})$

\subsubsection{Hardening and tempering}

The tempering process was done to transform unstable mártensite, for hardened, to stable martensite. Analysis using $\mathrm{X}$ - ray diffraction technique indicates that the structure of $0 \% \mathrm{Nb}$ content, is a matrix of tempered martensite and carbides $\left(\mathrm{Cr}_{23} \mathrm{C}_{6}\right)$ and no evidence of retained austenite, while the grade $\mathrm{D}$ steel, shows the presence of $\mathrm{NbC}$ in addition to $\mathrm{Cr}_{23} \mathrm{C}_{6}$.

\subsection{Hardness and tensile properties}

The variation of $\mathrm{HRC}$ with $\mathrm{Nb}$ content for different treatment processes is illustrated in Fig. 6. As shown in the figure. The hardness increased by increasing niobium content $(0-0.05 \%)$ microalloying element which forms hard and stable carbides. These carbides increased by increasing niobium content and hence increase hardness.

The figure also shows that, the annealed steel records the lowest hardness while the hardened shows the highest hardness level for all $\mathrm{Nb}$ contents.

The $\mathrm{Nb}$ content increases the hardness of all steel grades under investigation, while the HRC level becomes closer for hardened and hardened followed by tempering as shown in Fig. 7 .

The increase in hardness by the niobium addition is due to the formation of $\mathrm{NbC}$, the existence of stable martensite attributes the highest hardness for the hardening process. 


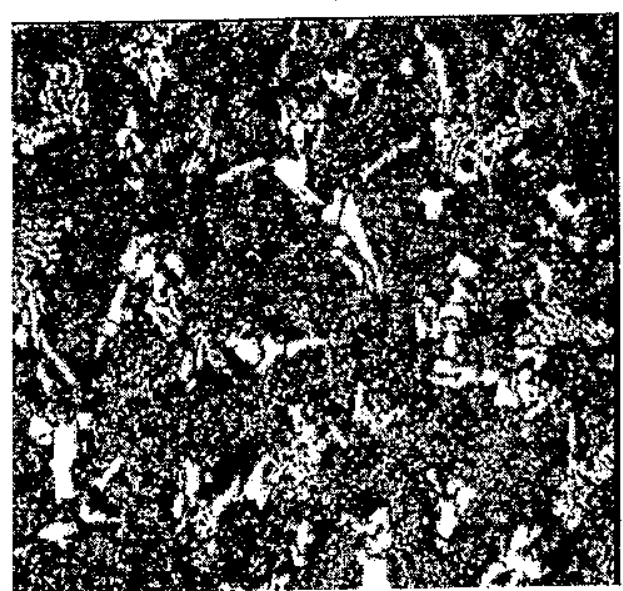

(a) grade $\mathrm{A}(0 \% \mathrm{Nb})$

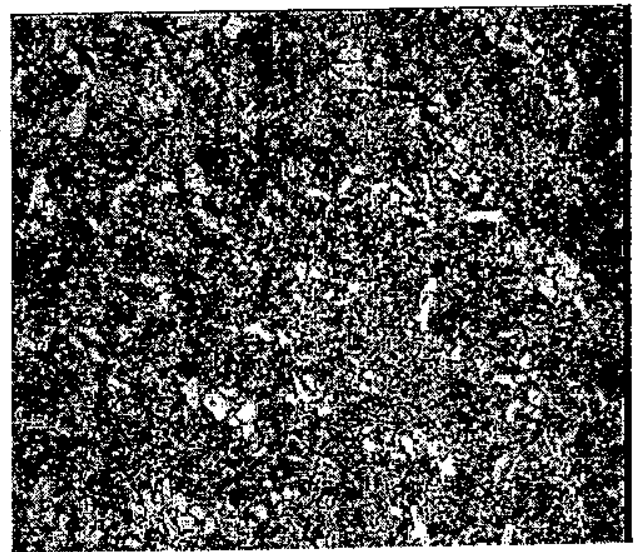

(b) grade $\mathrm{D}(0.05 \% \mathrm{Nb})$

Fig. 5 Microstructure of stress relief annealed steel $(500 \mathrm{X})$

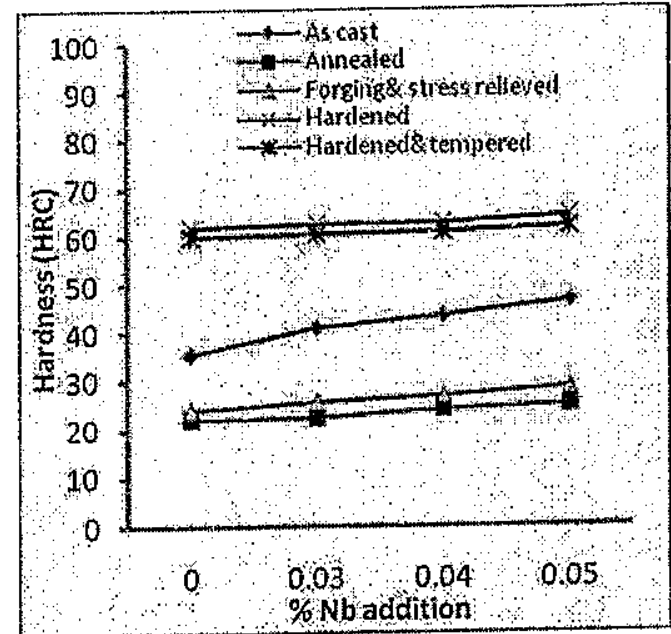

Fig. 6 Variation of $\mathrm{HRC}$ with $\% \mathrm{Nb}$ for different treatment processes

To evaluate the percentage change of hardness due to $\mathrm{Nb}$ addition and due to the subsequent heat treatment of as cast steel, the percentage hardness change with respect to steel grade $\mathrm{A}$ is shown in fig. 8a, and relative to as cast steel, has been plotted in Fig. 8 b.

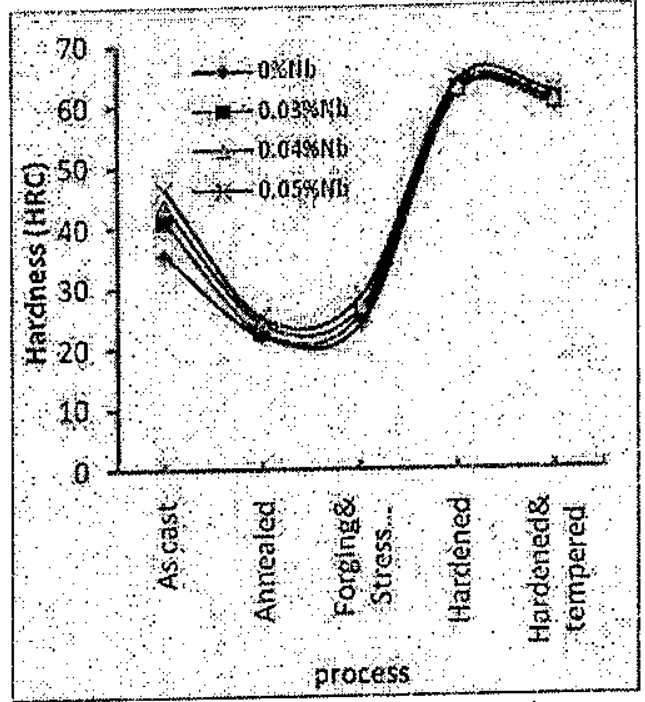

Fig. 7 Relation between HRC and steel treatment condition

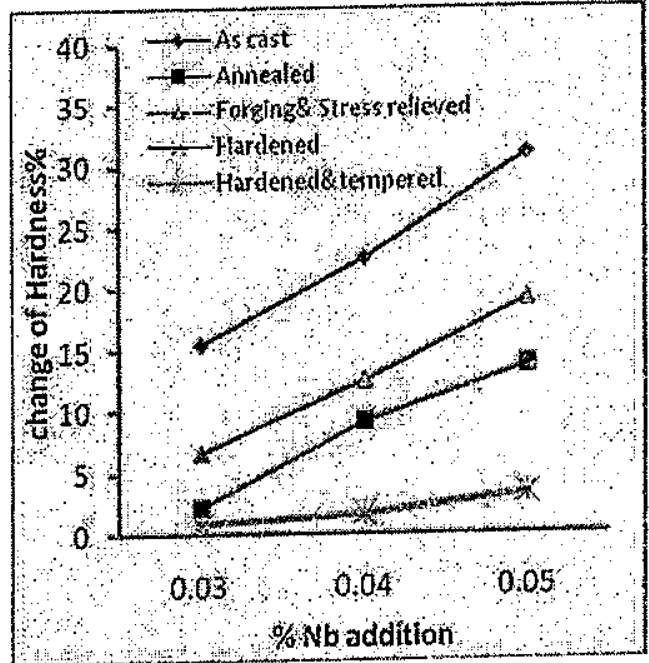

(a) with respect to grade $\mathrm{A}$, for different $\mathrm{Nb}$ addition

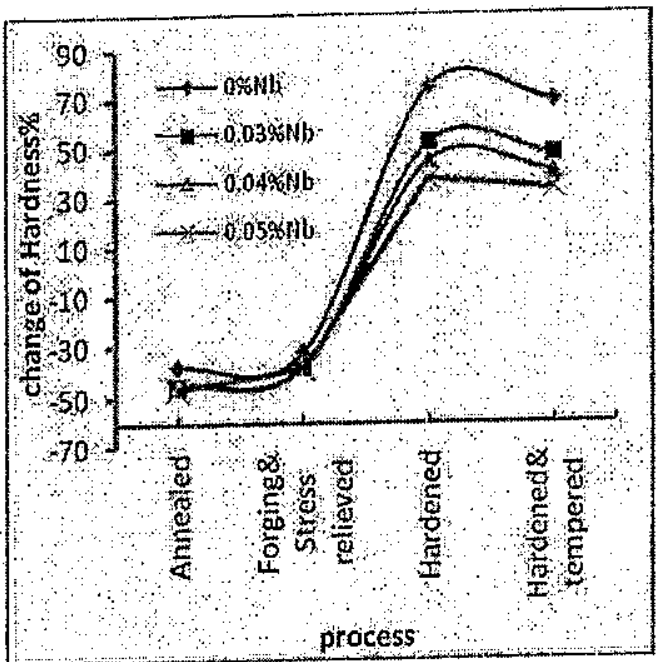

(b) with respect to as cast, for different treatments Fig. 8 Hardness percentage change 
It is clear from Fig. $8 \mathrm{a}$ that, the maximum enhancement percent $(31 \%)$ is recorded for steel grade D. figure Fig. $8 \mathrm{~b}$ shows that the hardness values after stress relief process decreased by $38 \%$ for grade $A$, by $45.1 \%$ for grade $B$, by $44.83 \%$ for grade $C$, and by 46.23 for grade $D$. the hardness values also decreased after annealing process by $(32.4 \%, 37.56 \%, 37.93 \%$, and $38.5 \%)$ for grade $A, B$, $\mathrm{C}$, and $\mathrm{D}$ respectively. Whilst, the hardness values increased due to hardening process by $74.65 \%$ for grade A, by $52.44 \%$ for grade B, by $44.83 \%$ for grade $C$, and by $37.63 \%$ for grade $D$. The same increased values were obtained after tempering process by $(69 \%, 47.56 \%, 40.23 \%$, and $33.33 \%)$ for grade $A, B$, $\mathrm{C}$, and $\mathrm{D}$.

\subsection{Tensile Properties}

Typical variation of the ultimate tensile strength (UTS) of different steel grades with $\mathrm{Nb}$ percent is shown in Fig.9. It is obvious that the highest UTS was achieved by the hardening process of grade $D$ steel $(0.05 \% \mathrm{Nb})$, which can be attributed to the strengthening by the formed niobium carbides.

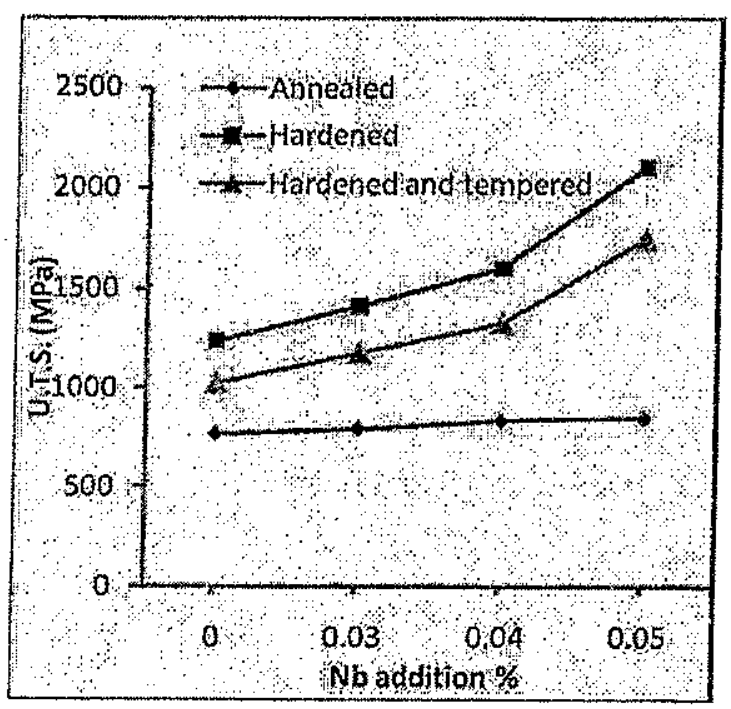

Fig. 9 Relation between UTS and Nb content for different treatment

A remarkable effect of niobium addition on the percentage improvement of UTS, relative to as cast $(0 \% \mathrm{Nb})$, especially for grade $\mathrm{C}$ and $\mathrm{D}$ steel, under hardening and tempering conditions is given in Fig. 10.

The highest percentage enhancement of UTS (70.43 $\%$ ) was recorded for hardened and tempered grade D steel.

The dependence of \% elongation on $\mathrm{Nb}$ content for different heat treatment processes is given in Fig. 11. The increase of $\%$ elongation with $\mathrm{Nb}$ content is based on grain refinement by niobium addition.

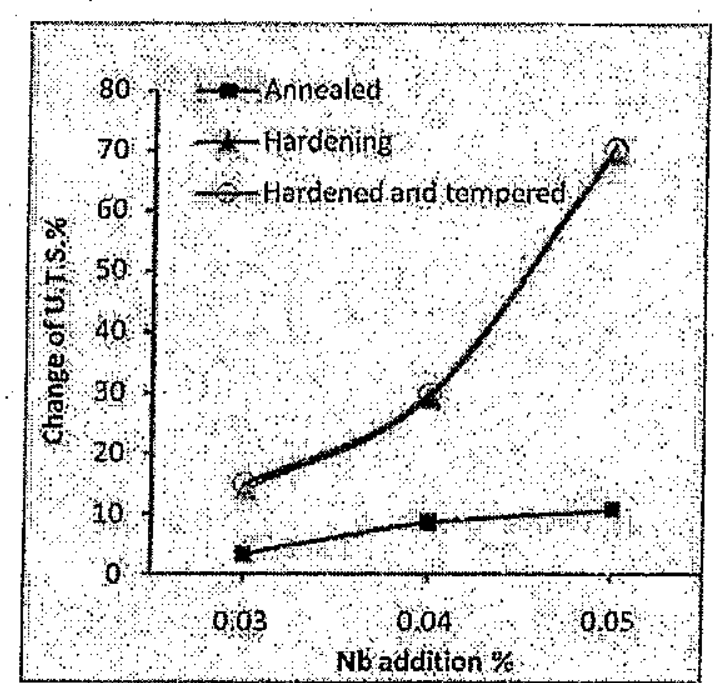

Fig. 10 Dependence of the \% UTS improvernent on $\mathrm{Nb}$ content

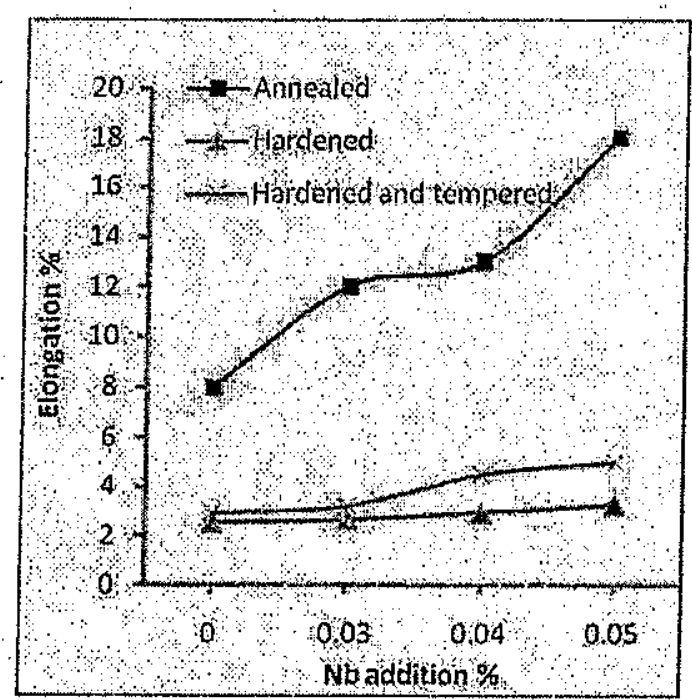

Fig.11 Effect of $\mathrm{Nb}$ addition on \% elongation for different treatment processes.

Fig. 12 represents the effect of heat treatment processes on \% elongation for different steel grades. The annealed steel shows the highest \% elongation, which can be attributed to the continuous ferrite matrix of the microstructure. This type of microstructure is easily deformed, therefore, it records the maximum \% elongation compared to the other heat treatment processes. Both of hardened steel and tempered steel indicate smaller \% elongation which can be attributed to the formation of martensite in hardened steel and tempered martensite in tempered steel. 


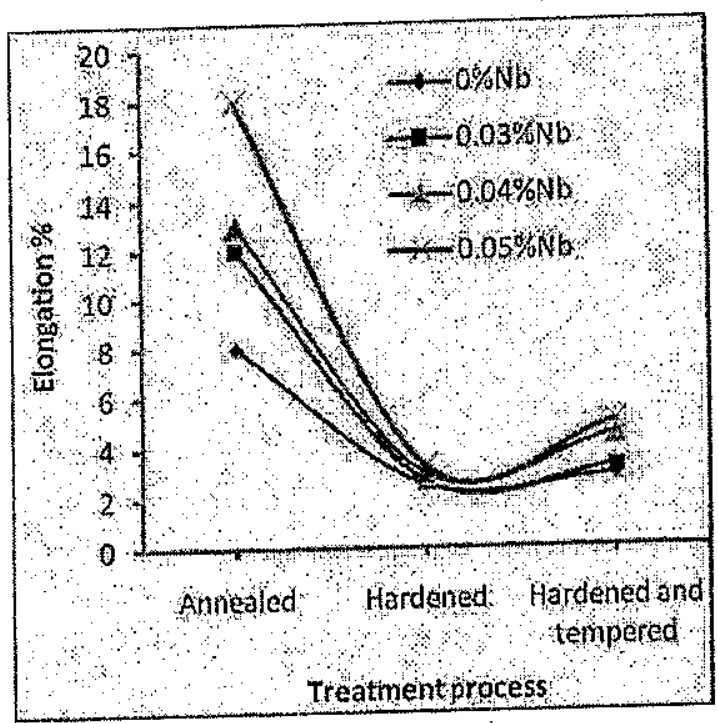

Fig. 12 Variation of $\%$ elongation with treatment processes for different $\mathrm{Nb}$ contents.

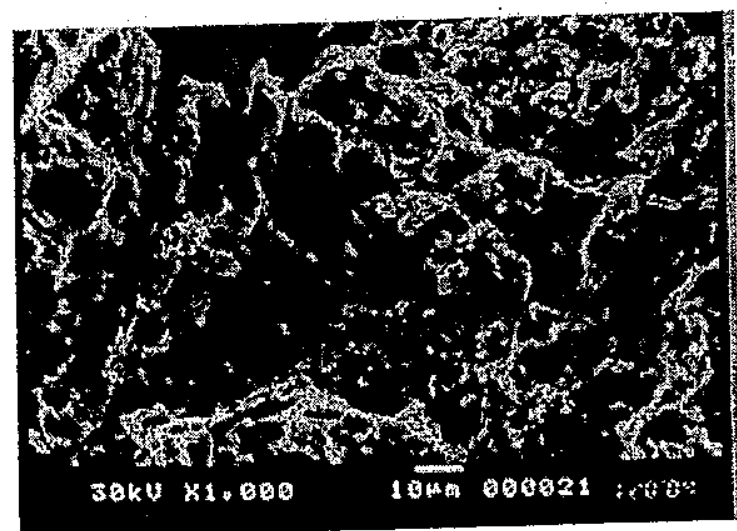

Grade A (0\% Nb)

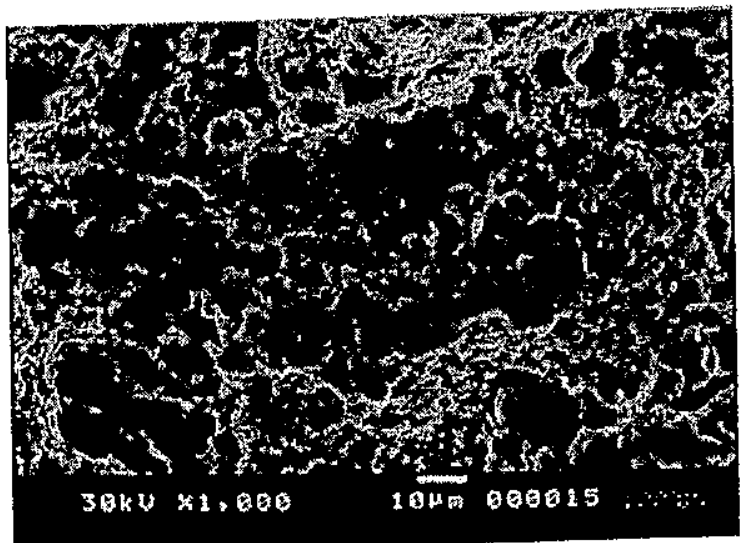

Grade $\mathrm{C}(0.04 \% \mathrm{Nb})$

\subsection{Fractographic Examination}

Essential information about the nature of fracture can be obtained by using the scanning electron microscope (SEM). The fractographic of annealed steel fracture surface of tensile specimens is shown in Fig.13.

As a result of the niobium addition, the cleavage fracture, shown in fig. 13 (a), becomes quasicleavage on dimples plus cleavage modes as it clear in fig. 13 (b-d).

Fig. 14 shows the fracture surfaces of hardened grade $A$ and grade $B$ steel. It is clear that, the dominate fracture mode is cleavage fracture due to the presence of carbides and martensite phase, which eliminate the effect of niobium addition.

On the other hand, the tempered steel shows a quasicleavage fracture mode as shown in Fig.15. Grade A steel shows a cleavage fracture mode, while ductile mode is the domain feature in grade $D$ steel as a result of niobium addition and the carbides particles serve as sits of fracture initiation.

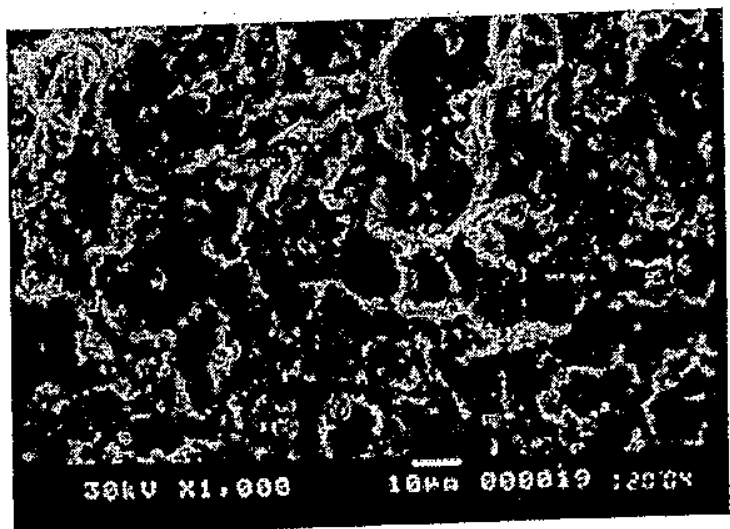

Grade $B(0.03 \% \mathrm{Nb})$

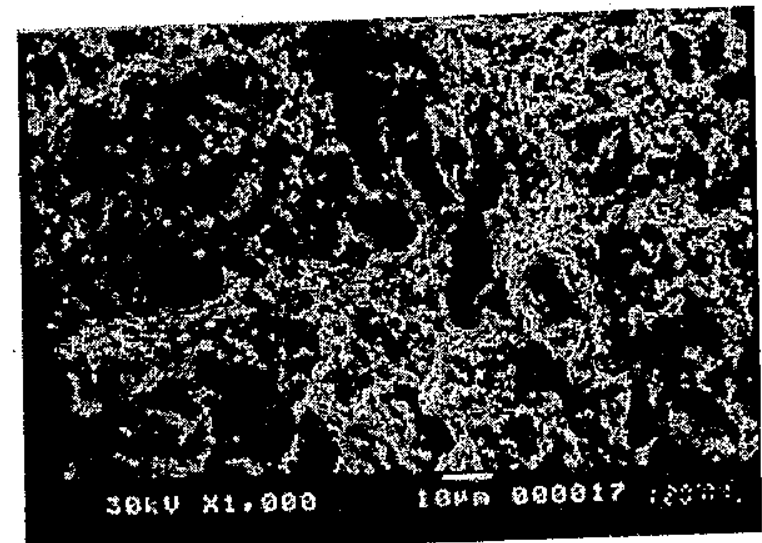

Grade $\mathrm{D}(0.05 \% \mathrm{Nb})$

Fig. 13 SEM microfractographs of annealed tensile specimen fracture surface 


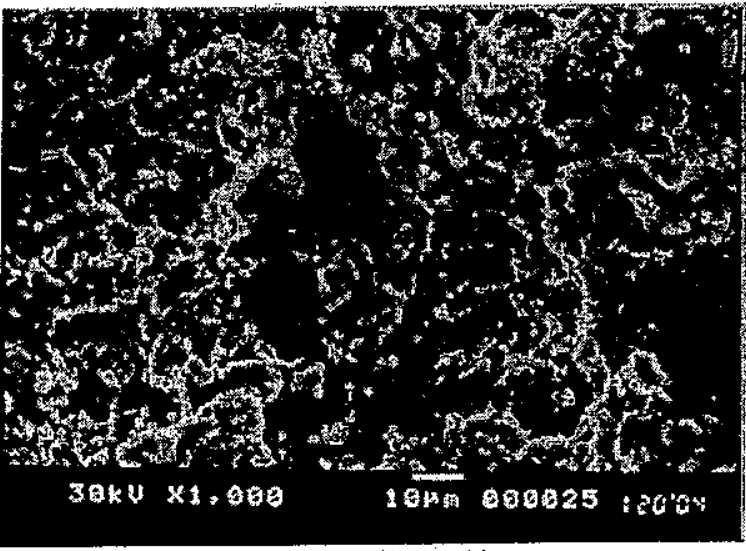

Grade $\mathrm{A}(0 \% \mathrm{Nb})$

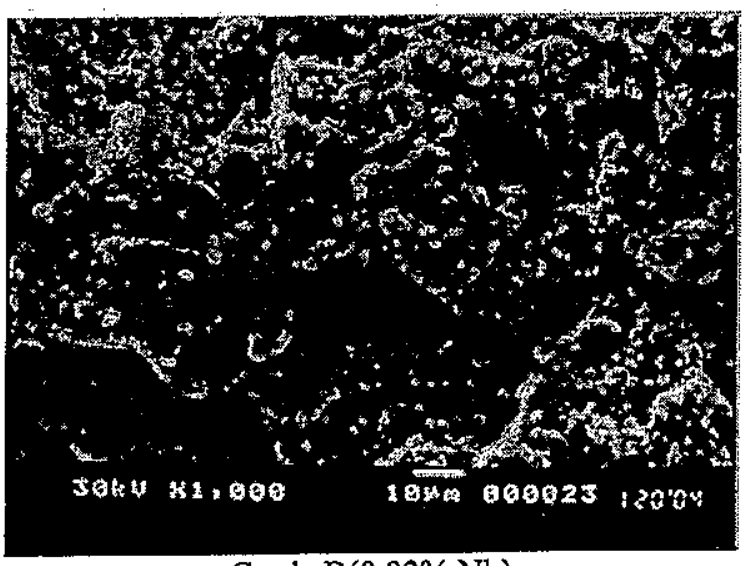

Grade $\mathrm{B}(0.03 \% \mathrm{Nb})$

Fig. 14 SEM microfractographs of hardened tensile specimen fracture surface

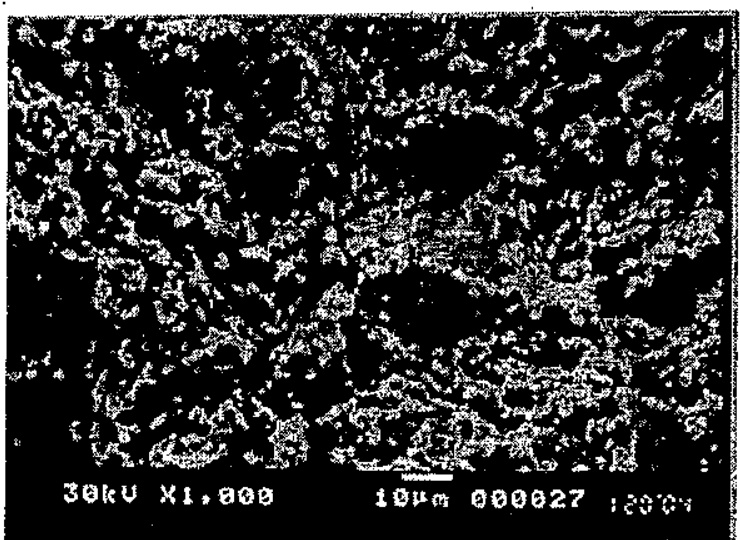

Grade $\mathrm{A}(0 \% \mathrm{Nb})$

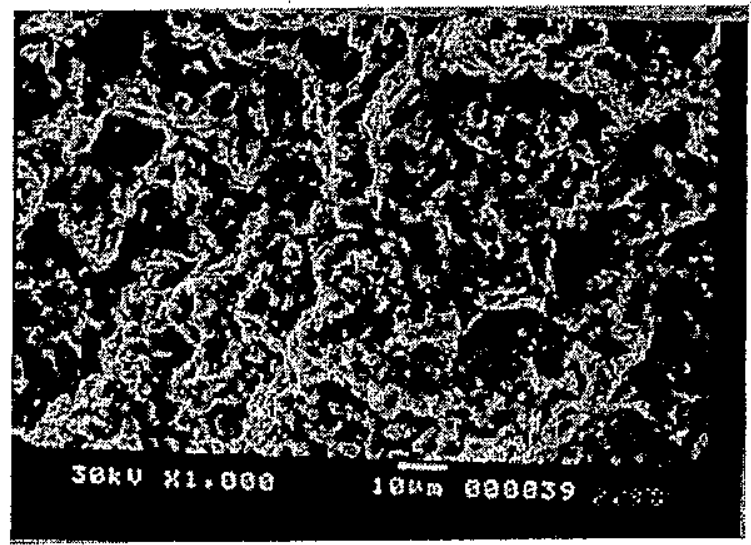

Grade C $(0.04 \% \mathrm{Nb})$

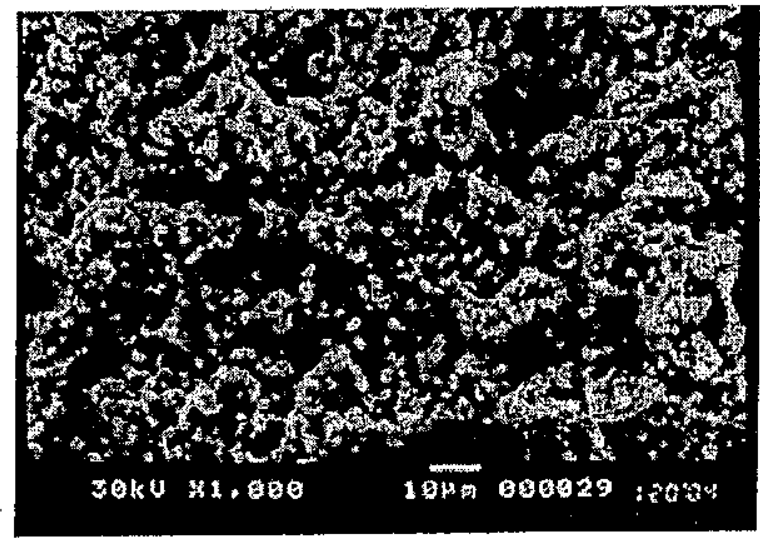

Grade $B(0.03 \% \mathrm{Nb})$

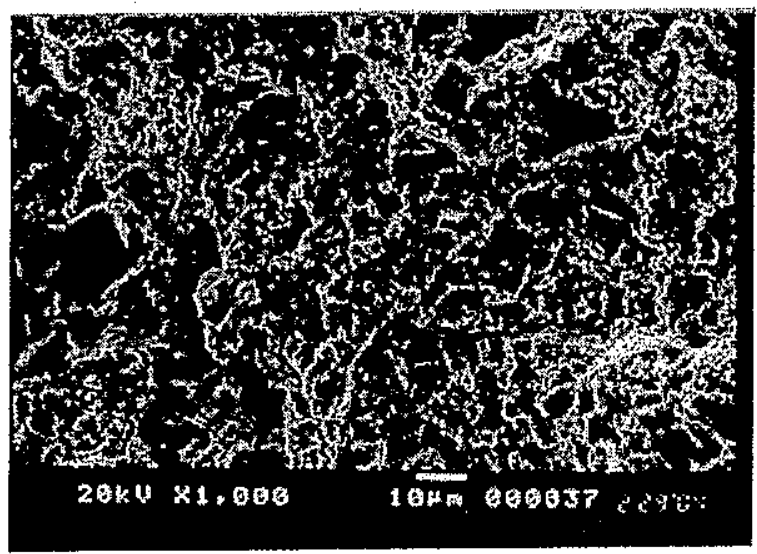

Grade D (0.05\% Nb)

Fig. 15 SEM microfractographs of tempered tensile specimen fracture surface

\subsection{Wear test results}

The variations of wear rate and dimensional wear coefficient, $\mathrm{K}$, with $\mathrm{Nb}$ content are shown in Fig. 16(a) and Fig. 16(b) respectively.

It obvious that, the different grades annealed steel show the highest wear rate, consequently gives the highest dimensional coefficient of friction. While the different grades tempered steel recorded the lowest wear rate and dimensional wear coefficient
Due to the presence of very hard primary chromium carbides in grade A steel (Fig. 5) the wear resistance of this steel grade is reduced as the hard carbide particles near the friction surface fall of during the friction process. The removed particles work as debris and lead to serious abrasive wear. The chromium carbides located in grade A steel are vulnerable to cracking to form microcracks even under low applied stress (Fig. 14, and Fig. 15). On the other hand, $B$ to $D$ steel grades (0.03 to 0.05 
$\% \mathrm{Nb}$ ), are composed of eutectic carbides (niobium carbides) instead of primary carbides.

Fig. 16 (a, and $b)$, indicates that, the hardening and hardening followed by tempering increases the resistance to wear rate and consequently dimensional wear coefficient. The tempering process produces continuous films of interlath refined austenite transform to iron carbide. These carbides limit the plastic zone deformation in front of crack to the width of the martensite lath which decreases the wear rate of tempered steel.

Fig. 17 compares the results of the dimensional wear coefficient of steel grades $(B-D)$ with that of annealed grade $A$ steel. In general, the heat treatment process remarkably decreases the dimensional wear coefficient $(\mathrm{K})$, and the maximum enhancement of wear resistance can be achieved by hardening followed by tempering.

The hardened and tempered grade $D$ steel records almost $100 \%$ wear resistance improvement.

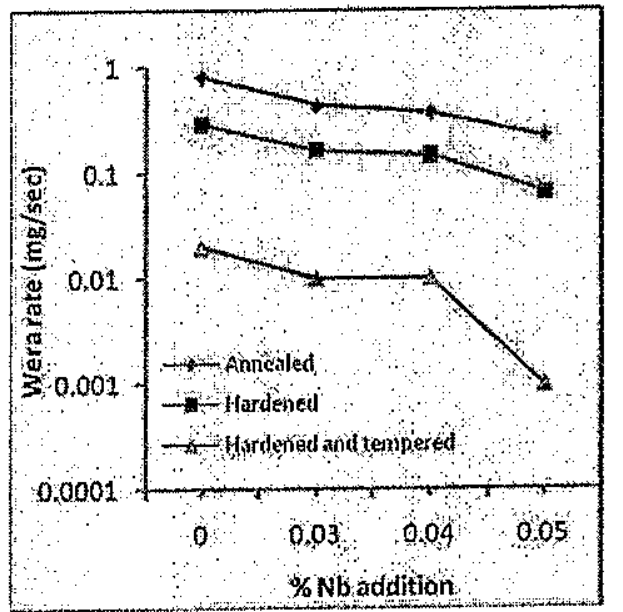

(a) wear rate

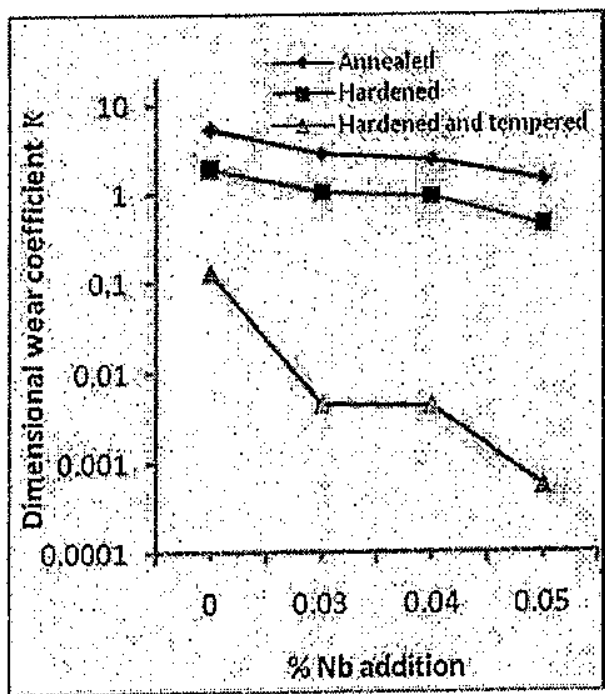

(b) dimensional wear coefficient

Fig. 16 Variations of wear rate and coefficient, $\mathrm{K}$ with $\% \mathrm{Nb}$

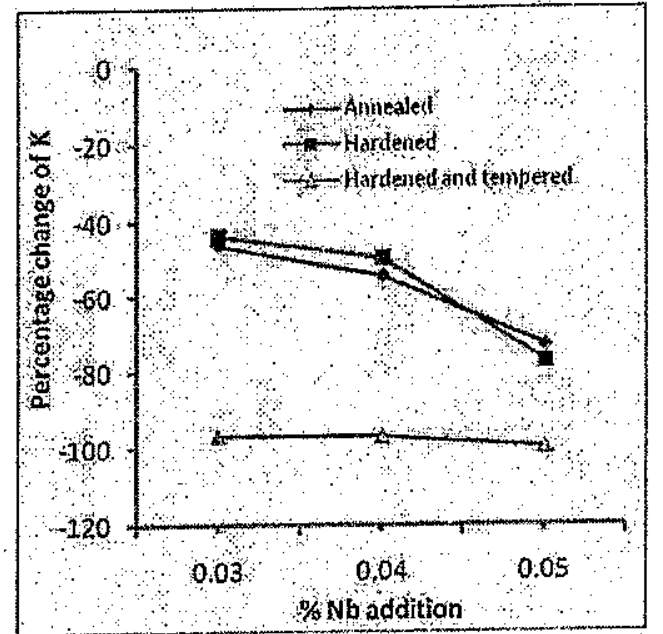

Fig. 17 Relation between \% enhancement of wear resistance for different treatment processes

\section{CONCLUSIONS}

Based on the present investigation, the followings can be concluded;

1- Niobium is an effective microalloy for grain refinement by controlling the austenite grain size during the reheating process during heat treatment cycle.

2- Addition of $0.05 \% \mathrm{Nb}$, increases the tensile strength and elongation to much higher values, $(70.34 \%$, and $72.41 \%$ respectively higher than the standard grade), at different heat treatment processes with respect to grade $A$.

3- Grade $\mathrm{D}$ (with $0.05 \% \mathrm{Nb}$ ) tool steel shows the highest increase in hardness, and tensile strength, over the standard grade $(33.33 \%, 70.43 \%$; respectively).

4- The percentage elongation is increased with the increase of $\mathrm{Nb}$ content.

5- Grade D (with $0.05 \% \mathrm{Nb}$ ), give a higher wear resistance.

6- Hardening followed by tempering process causes the highest wear resistance especially for $0.05 \% \mathrm{Nb}$ steel.

7- Addition of few amount of ferroniobium (0.05\%) as in grade $\mathrm{D}$, is expected to improve the stamping tool life

\section{REFERENCES}

[1] Engel, U., V" olkl, R., Arbak, M., "Current state of progress in predicting performance and reliability of cold forging tools", In: Kuzman, K. (Ed.), Conference Proceedings ICIT 2003 4th International Conference on Industrial Tools. Bled Celje, Slovenia, pp. 43-48, 2003.

[2] Wagner, K., V" olkl R., U. Engel "Tool life enhancement in cold forging by locally optimized 
surfaces", journal of materials processing technology $201, \mathrm{pp}(2-8), 2008$.

[3] Popp, U., Engel, U. "Micro texturing of cold forging tools-influence on tool life", J. Eng. Manuf. 220 (1), pp(27-33), 2006.

[4] Munoz Riofano, R.M., Casteletti, L.C. , Canale, L.C.F., Totten, G.E. "Improved wear resistance of $\mathrm{P} / \mathrm{M}$ tool steel alloy with different vanadium contents after ion nitriding" Wear $265 \mathrm{pp}(57-64)$, 2008.

[5] Berns, H. and Trojahn, W., "New cold working tool steel", Institut fur. Werkstoffe, Lehrstofftechink, Ruhr- Universitat, Bochum, Fondry congress, 11-13, November. 1985,

[6] Hutching I. M.,. "Tribology; Friction and wear of Engineering Materials". Edward Arnold, 1992. 